\title{
Ergonomic requirements for the operation of machines and technical equipment
}

\author{
Adam Górny ${ }^{1 *}$ \\ ${ }^{1}$ Poznań University of Technology, Faculty of Management Engineering, 11 Strzelecka St., room \\ 318/2, PL-60-965 Poznań, Poland
}

\begin{abstract}
In order to operate machinery and equipment safely, it is critical for the solutions in place to conform to design-related and operating requirements. Design-related requirements are primarily the responsibility of machine designers/developers and manufacturers. Operating requirements should be satisfied by employers, who are responsible for ensuring safe working conditions for their employees. Under applicable laws, machinery and equipment should be designed, produced and then operated without placing excessive loads on workers and in keeping with machine functionality and intended use. One should also ensure that machinery and equipment can be maintained and adjusted without exposing their operators to hazards. Ergonomic criteria are an integral part of such requirements. They ensure that human users and operators of technical equipment are enabled to function properly. Designrelated requirements are viewed as a priority safety consideration. While they facilitate the use of technical tools, the actual safety of employees ultimately depends on the satisfaction of specific requirements during operation.
\end{abstract}

\section{Introduction}

Employers have the responsibility to ensure safe and healthy working conditions for their employees. This obligation includes fitting workstations with machinery and equipment that meets safety requirements $[1,2]$. The requirements themselves are not new. However, recent years have seen significant changes in the approach to their implementation [3-6] prompted by the requirement to account for the needs of specific employee groups [7, 8] and doing work without hazards [9-11].

The key to securing safe operation of machinery and equipment are essential requirements, which make their proper use possible. To ensure safe operation, it is crucial to fulfill the minimum criteria guaranteeing minimal safety levels, as required by the European Union $[4,12,13]$.

An integral part of the minimum requirements are ergonomic criteria designed to create an environment for the efficient operation of equipment without hazards and excessive strains.

\footnotetext{
*Corresponding author: adam.gorny@put.poznan.pl
} 


\section{Operating safety guidelines}

Work requires resources which make possible its performance without excessive strenuousness and impediments. Such resources include tools and equipment in the workplace $[14,15]$. One significant requirement for machinery and equipment design is to account for knowledge on people's psychological and physical capabilities. Once fulfilled, the requirements guarantee safe operation. A central factor for the desired level of safety is to achieve compliance with mandatory laws and regulations.

Such compliance should be viewed as the most fundamental prerequisite for the safe operation of technical equipment. It applies to proper design and development as well as rules governing equipment operation. The essence of applying such requirements in conjunction with the principles of ergonomics has been captured in Figure 1.

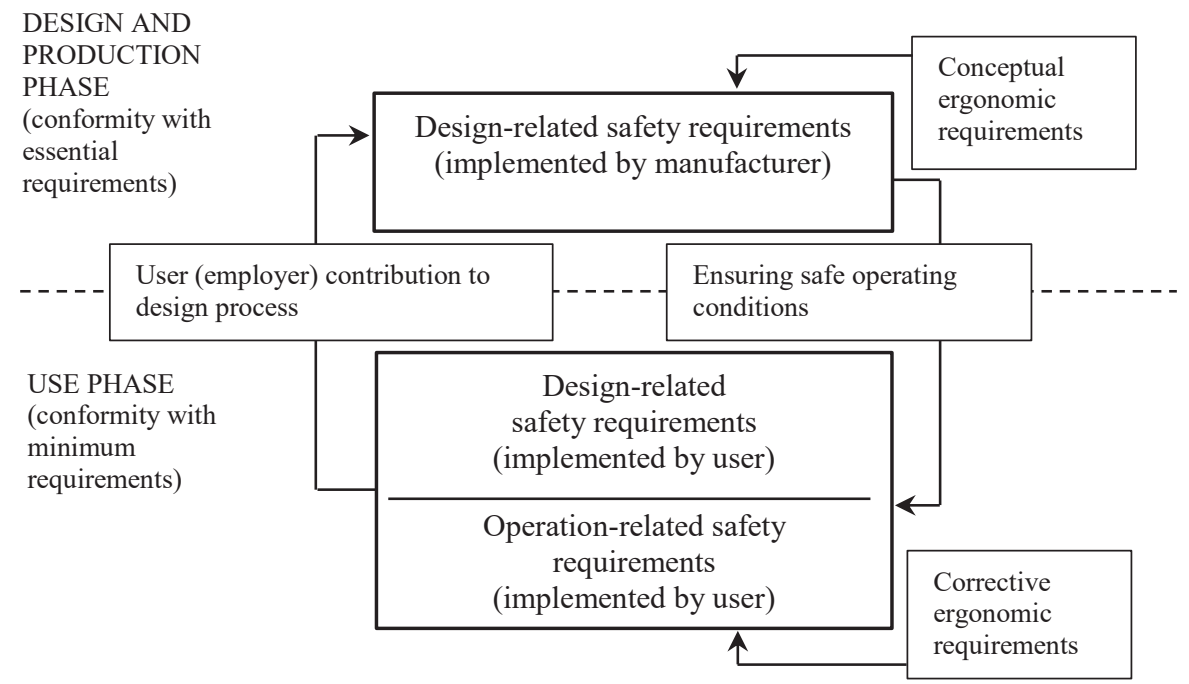

Fig. 1. Implementation of safety requirements (in conjunction with the principles of ergonomics) during the design and operation of machinery and equipment.

Adherence to ergonomic requirements helps reduce work strenuousness, achieve comfort and boost workers' ability to operate machinery and equipment efficiently [16]. To ensure the safe operation of technical equipment, it is critical to comply with:

- Anthropometric requirements applying to the adjustment of technical equipment to match the size and weight of the human body,

- Physiological requirements applying to the adjustment of technical equipment to match physiological characteristics, such as muscular loads,

- Psychophysical requirements, associated with human senses,

- Hygienic requirements, designed to promote working comfort.

To deploy the above measures effectively, organizations need to put in place a proper surveillance system to monitor operation and apply improvement measures where necessary. 


\section{Role of ergonomic criteria}

\subsection{Ergonomic criteria within the essential requirements}

Essential requirements should be seen as common (EU-wide) and critical for the safe operation of machinery and equipment. Their responsibility for their incorporation into machine design and development rests with the manufacturer.

Essential requirements refer, inter alia, to materials, control and supervision, operator postures, visibility, lighting, etc. The tools and equipment used at work should accommodate user needs. It is therefore vital to be aware of human characteristics, people's physical and mental performance levels, acceptable physical and psychological loads, body sizes and build types as well as capabilities and skills [1, 5, 4, 17-20]. Significant design issues include machine-to-man information transfers, human handling of machines by means of controls and conformity with anthropometric requirements applicable to technical equipment [21].

In the course of design, whose outcomes need to comply with mandatory laws, organizations should identify the safety requirements whose satisfaction will help achieve the desired operating parameters and define the scope of improvement measures [2].

In order to satisfy ergonomic criteria, proper reference needs to be made to the conditions in which humans operate in the work environment. By accounting for ergonomic requirements, organizations can define the extent to which the level of conformity they achieve can be expected to reduce waste and improve performance capacities [1]. Ergonomic conformity should minimize adverse effects of work such as injuries, diseases and errors. This is the result of reducing strains brought about by failures to create proper conditions for the performance of tasks and processes $[3,12]$. It is equally crucial to create an esthetically pleasing environment that motivates workers to work effectively and safely [21].

\subsection{Ergonomic criteria in minimum requirements}

Minimum requirements are defined as mandatory conditions for the operation of technical equipment. They may be viewed as fundamental for ensuring worker safety and proper technical condition and serviceability at all work stages $[2,5,13,17]$. Such requirements do not go as far as more stringent safety requirements (such as industry requirements), which employers may find necessary to e.g. minimize accident-related losses $[12,13]$.

Minimum requirements apply, among others, to shape, color, touch, size, and current situation assessment. Through their satisfaction, organizations lower risks to acceptable levels. The key aim is to comply with statutory/regulatory requirements and optimize loads.

A significant part of minimum requirements are ergonomic criteria, which help meet user expectations and consequently boost work efficiency. They are stipulated in legal requirements and normative technical criteria. Ergonomic requirements point to the need to accommodate user needs and other factors contributing to working comfort. Their nature makes such requirements particularly critical for ensuring efficient information flows between technical equipment (machines) and man (operator) $[11,20,22]$. The dependencies that arise can be identified through criteria determining the ability to perform work. These may be seen as hazard mitigators and a necessary condition for having technical equipment approved for use.

\section{Practical aspects of conformity with ergonomic requirements}

The job of an employer is to launch measures aimed at ensuring that the tools and equipment provided to workers are fit for use and properly adjusted to meet specific 
performance demands [12]. In selecting equipment, it is crucial to recognize the conditions and nature of work as well as any work safety hazards $[2,13]$.

Organizations seeking to comply with ergonomic requirements must account for the conditions in which technical equipment is used as well as other significant factors affecting users' ability to operate in the work environment $[1,2]$. To that end, they should [20]:

- Accommodate the physical features of operators, including their strength and endurance,

- Provide sufficient room to allow operators to move freely,

- Avoid forcing operators to perform work at a pace imposed by machines,

- Avoid work in unnatural or forced postures or postures maintained over extended periods,

- Avoid forcing concentration over prolonged periods to monitor operation,

- Adjust the man-machine interface to predictable operator characteristics,

- Allow freedom in the performance of work without forcing workers to behave unnaturally due to organizational constraints.

Regardless of the solution-selection methodology that organizations adopt, they must verify their ability to ensure safe operation. Such safety audits identify discrepancies between the existing and desired states and, with respect to ergonomic requirements, the effectiveness achieved in preventing excessive loads. Ultimately, the audits show what kinds of solutions have been adopted and whether they are sufficient to ensure compliance with requirements relating to the operation of machinery and equipment. In conducting such audits, one should bear in mind that operating safety rests also on machine and device reliability [2]. In this sense, one can speak not only about designing appropriate solutions but also about ensuring proper conditions for their deployment.

Guidelines for the scope of audits of conformity with ergonomic and operating safety requirements are summarized in Table 1.

Table 1. Scope of audits verifying the safety of machinery and equipment operation.

\begin{tabular}{|l|l|}
\hline \multicolumn{1}{|c|}{ Specification } & \multicolumn{1}{c|}{ Description } \\
\hline Exposed individuals & $\begin{array}{l}\text { Persons who can reasonably be described as exposed to the impacts of } \\
\text { irregularities associated with the operation of machinery and equipment, }\end{array}$ \\
\hline $\begin{array}{l}\text { Exposure type, } \\
\text { frequency and } \\
\text { duration }\end{array}$ & $\begin{array}{l}\text { Factors associated with access to hazard zones during entry to adjust } \\
\text { settings, program, modify and correct process parameters, maintain and } \\
\text { clean machinery and equipment, }\end{array}$ \\
\hline $\begin{array}{l}\text { Relationship } \\
\text { between exposure } \\
\text { and actual effects }\end{array}$ & $\begin{array}{l}\text { Requires the organization to identify adverse work-related factors and the } \\
\text { effect of accumulated exposures to risk factors and any related synergies, }\end{array}$ \\
\hline Human factor & $\begin{array}{l}\text { Associated with the direct application of ergonomic requirements in } \\
\text { machine design, building and equipping; recognition of worker } \\
\text { inclinations to deviate from safety procedures, }\end{array}$ \\
\hline $\begin{array}{l}\text { Reliability of safety } \\
\text { devices and systems }\end{array}$ & $\begin{array}{l}\text { Requires the identification of circumstances potentially leading to waste } \\
\text { (such as damage to items of critical importance for proper performance, } \\
\text { electric power failures and power supply disruption), }\end{array}$ \\
\hline $\begin{array}{l}\text { Danger of safety } \\
\text { measure failure }\end{array}$ & $\begin{array}{l}\text { Associated with the application of safety measures that reduce work } \\
\text { efficiency and effectiveness, }\end{array}$ \\
\hline $\begin{array}{l}\text { Ability to keep } \\
\text { means of ensuring } \\
\text { safety in proper } \\
\text { condition }\end{array}$ & $\begin{array}{l}\text { Requires an indication of whether the existing safety precautions can be } \\
\text { maintained to an adequate safety standard }\end{array}$ \\
\hline $\begin{array}{l}\text { Information } \\
\text { regarding use }\end{array}$ & $\begin{array}{l}\text { Associated with the availability of information on machine use, } \\
\text { especially when it is critical for the effectiveness of the safety measures } \\
\text { in place }\end{array}$ \\
\hline
\end{tabular}

The results of the ergonomic and safety evaluation of the controls of the eccentric press referred to in Figure 2 are shown in Table 2. 


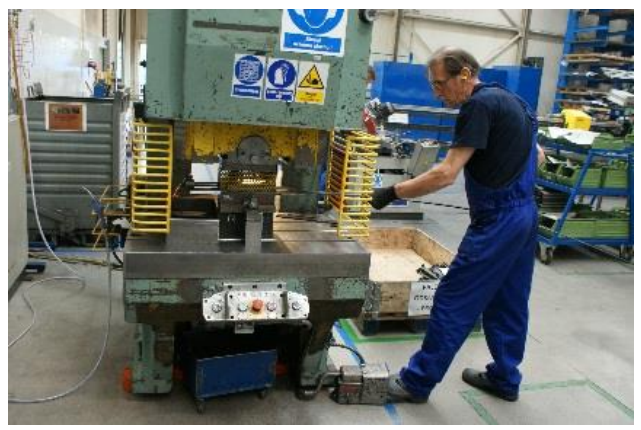

Fig. 2. The eccentric press whose controls were assessment.

Table 2. Assessment of solutions in place.

\begin{tabular}{|l|}
\multicolumn{1}{c|}{ Sample identified non-conformities } \\
\hline - During work performance (and specifically when handling machine controls), additional \\
personnel enter the hazard zone and become exposed to hazards, \\
- The way the controls are operated does not eliminate having to access the hazard zone, \\
- To access controls, workers are forced to work in awkward bending postures, \\
- Controls descriptions and labels do not ensure an unambiguous identification of controls, \\
- Controls descriptions and labels fail to meet requirements concerning e.g. font size and \\
operator's native language, \\
- The available work manual does not clarify the meaning of symbols on press controls. \\
\hline
\end{tabular}

\section{Conclusion}

For the safety of persons exposed to risks during the operation of machinery and equipment, it is essential to ensure that ergonomic requirements are adequately satisfied. Such satisfaction can be achieved by employing specific design solutions or, should that be impossible, by incorporating proper safeguards into machinery and equipment (collective protective equipment) [13].

If the existing improvement measures are aimed at mitigating the risks that result from the machines failing to meet worker needs, an ergonomics audit is in order to verify the choice of such measures. Any follow-up steps should be proportionate to the extent of the problem while ergonomic requirements should constitute improvement guidelines specifying the need for change.

To achieve conformity with requirements that account for ergonomic criteria at the operational stage, organizations need to employ corrective ergonomics to make sure their existing solutions offer a sufficient response to any non-conformities with operational requirements without contributing to adverse impact on workers $[1,12,13]$. In such circumstances, it is essential to recognize employee needs, whose satisfaction is central for efficient work performance.

\section{References}

1. A. Górny, Procedia Manufacturing 3, 4700-4707 (2015)

2. A. Górny, B. Mrugalska, CCIS 374, 494-498 (2013)

3. A. Mazur, H. Gołaś, A. Rosińska, M. Drzewiecka, Quality improvement of products,. $117-130(2011)$

4. B. Mrugalska, P. Arezes, Work 51(4), 747-755 (2015) 
5. Directive 2006/42/EC of the European Parliament and of the Council of 17 May 2006 on machinery, and amending Directive 95/16/EC (recast); OJ L 157, 9.6.2006, 24-86 (2006)

6. Directive 2009/104/EC of the European Parliament and of the Council of 16 September 2009 concerning the minimum safety and health requirements for the use of work equipment by workers at work (second individual Directive within the meaning of Article 16(1) of Directive 89/391/EEC); OJ L 260, 3.10.2009, 5-19 (2009)

7. M. Butlewski, M., Applied Mechanics and Materials, 657, 1061-1065 (2014)

8. M. Rembiasz, MATEC Web of Conferences, 94, 07009 (2017)

9. A.M. Lasota, K. Hankiewicz, Occupational Safety and Hygiene, SHO 2016, 261-264 (2016)

10. A.M. Lasota, K. Hankiewicz, Occupational Safety and Hygiene, SHO 2016, 138-140 (2016)

11. A. Misztal, M. Butlewski, A. Jasiak, S. Janik, Metalurgija 54(2), 429-432 (2015)

12. A. Górny, Occupational Safety and Hygiene, SHO 2013, 164-165 (2013)

13. A. Górny, Occupational Safety and Hygiene, 497-501 (2013)

14. A. Górny, MATEC Web of Conferences 94, 04011 (2017)

15. R. Chaib, I. Verzea, I. Cozminica, M. Bendir, Safety Science 76, 145-150 (2015)

16. P.M. Arezes, A.S. Miguel, Ergonomics in Contemporary Enterprise, 47-56 (2007)

17. K.P. Hankiewicz, J.S. Marcinkowski, Advances in Industrial Ergonomics and Safety, part III, 701-708 (1991)

18. G.H. Choi, Safety and Health at Work 8(1), 59-66 (2017)

19. K.K. Milovanovic, A.K. Arsic, I. Savovic, $6^{\text {th }}$ International Quality Conference, 927938 (2012)

20. EN ISO 12100:2010 (PN-EN ISO 12100:2012), Safety of machinery. General principles for design. Risk assessment and risk reduction, PKN, Warsaw (2012)

21. J.R. Wilson, H.M. Hains, Participatory ergonomics, In: G. Salvendy (ed.), Hendbook of the Human factors and Ergonomics (Wiley, Chichester, 1977)

22. A. Górny, Zeszyty Naukowe Politechniki Poznańskie, Seria: Organizacja i Zarządzanie 63, 51-66 (2014) 